\title{
Investigación cualitativa en el campo de la salud: un paradigma comprensivo
}

\author{
Qualitative research in the field of health: \\ an understanding paradigm
}

\author{
Teresa Millán Klüsse
}

aUniversidad de Chile, Facultad de Medicina, Departamento de Pediatría y Cirugía Infantil Occidente

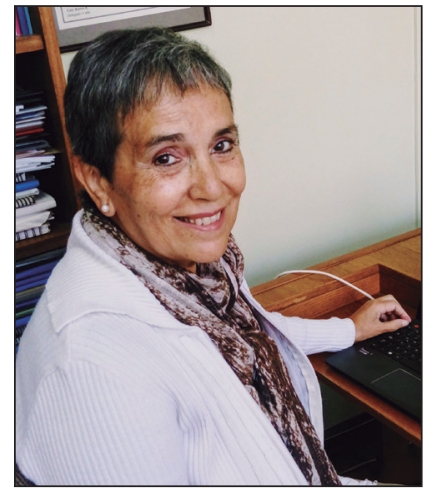

Una de las primeras cuestiones que se plantea el investigador frente a la detección de un problema y la pregunta de investigación, es reconocer algunos aspectos que le permiten identificar de qué se trata el problema y cuál es el método que elegirá para responder a la pregunta. Será la aplicación de metodología cuantitativa o será la metodología cualitativa, o serán ambas. Ello dependerá de ciertos criterios que definen y ayudan a caracterizar el ámbito de la pregunta, como por ejemplo, si lo que se desea conocer es la magnitud de un fenómeno o su naturaleza, o si se desea conocer el promedio o su estructura dinámica, o es el descubrimiento de leyes o la comprensión de fenómenos humanos, o es la adecuación del modelo teórico con la estructura de la realidad, o es el nivel de generalización, o finalmente si es la integración de lo cualitativo y lo cuantitativo $^{1-5}$.

Una vez identificado que el problema y la pregunta tienen respuesta en el comportamiento del ser humano, el segundo desafío para los investigadores está en abordar el fenómeno detectado desde una dimensión naturalística y fenomenológica que le permita la comprensión de los problemas de salud que están afectando a la población.

Es esa dimensión fenomenológica la que caracteriza a la investigación cualitativa, interesada en comprender la conducta humana desde el propio marco de re- ferencia de quien actúa. Se ha venido configurando en forma progresiva a lo largo del siglo XX en las ciencias sociales y humanas y paralelamente a los desarrollos de la filosofía de la ciencia, con un enfoque asociado a perspectivas epistemológicas y teóricas, de corte interpretativo y sociocrítico. Acompañada de históricos debates que la hacían aparecer como en oposición con el enfoque cuantitativo racionalista, sube al rango de paradigma a mediados de los años 80. En 1971 Denzin selló la frase "indagación naturalista" para contrastar con el enfoque predominante experimental de "indagación convencional”. En la actualidad la discusión ha ido evolucionando hacia la acomodación o complementariedad entre el paradigma positivista y el interpretativo $^{2,3}$.

Intentar definir la investigación cualitativa es complejo, por los múltiples usos y significados que ha adoptado a lo largo de la historia y a la gran variedad de componentes y atributos que la conforman, lo cual ha llevado a que diversos autores prefieran describir sus características como una forma de aproximación a su comprensión.

Una descripción que aportan Denzin y Lincoln (1994), la más reproducida en las obras sobre metodología cualitativa es la siguiente: "la investigación cualitativa es un campo interdisciplinar y en ocasiones contradisciplinar. Atraviesa las humanidades, las cien- 
cias sociales y las físicas. La investigación es muchas cosas al mismo tiempo. Es multiparadigmática en su enfoque. Las personas que la practican son sensibles al valor de un enfoque multimétodo. Están comprometidas con una perspectiva naturalista y una comprensión interpretativa de la experiencia humana". Al mismo tiempo, el campo de la investigación cualitativa es inherentemente político y se perfila a través de múltiples posiciones éticas y políticas. La investigación cualitativa abarca dos tensiones. Por un lado supone una amplia sensibilidad interpretativa, postmoderna, crítica y por otro, recoge una estrecha definición de las concepciones positivistas, post positivista, humanística y naturalistica de la experiencia humana y su análisis ${ }^{1-3}$.

Actualmente la investigación cualitativa está siendo cada vez más utilizada en el campo de la salud, para abordar sobre todo los problemas de enfermedades crónicas, producto de los estilos de vida no saludables de la población durante el curso de vida, cuyos orígenes, causas y respuestas, de cómo intervenir y modificar su evolución se encuentra en la comprensión del comportamiento de las personas. Poder entrar al mundo subjetivo indagando en profundidad las conductas del ser humano, con diversas técnicas metodológicas, requiere del rigor científico que ésta metodología ha levantado e indudablemente de la experiencia de los investigadores.

Aproximarse a indagar en la intimidad de las personas respecto a qué piensan, qué sienten, cómo actúan, qué los mueve a tomar decisiones, cuáles son sus actitudes y percepciones frente al medio que los rodea, son parte de lo que pretendemos comprender.

La pregunta que constituye el objeto de la investigación cualitativa orientada a la comprensión puede tener múltiples respuestas tales como comprender las conductas naturales para descubrir leyes; situaciones sociales identificadas por el lugar, los actores y las actividades; significados de textos y acciones; procesos de interacción social entre sociedad y personas, análisis

Tabla 1. Investigación cualitativa. Revista Chilena Pediatría

\begin{tabular}{lccc}
\hline Años & $\begin{array}{c}\text { Artículos } \\
\text { cualitativos }\end{array}$ & $\begin{array}{c}\text { Total } \\
\text { originales }\end{array}$ & $\begin{array}{c}\text { Artículos } \\
\text { cualitativos\% }\end{array}$ \\
\hline $2002-2004$ & 1 & 61 & 1,6 \\
$2005-2007$ & 1 & 69 & 1,4 \\
$2008-2010$ & 1 & 66 & 1,5 \\
$2011-2013$ & 4 & 81 & 4,9 \\
$2014-2016$ & 1 & 95 & 1,1 \\
$2017-2018^{*}$ & 4 & 51 & 7,8 \\
\hline
\end{tabular}

*Revistas No 1 al 5 de la cotidianidad; construcción de sistemas semánticos en individuos y grupos que son expresión de su conocimiento cultural; patrones culturales de un grupo identificando creencias y prácticas concretas de su organización social, estructura familiar, educación, rituales, religión ${ }^{2}$.

Un aspecto importante que deben considerar los investigadores cualitativos es estar conscientes que el rol que juegan, forma parte del ser instrumento de la investigación. Esto conlleva problemas en el sentido de convertirse el investigador, en persona tan cercana y conocedora de las realidades que está investigando, que corre el riesgo de transformarse en "nativo", esto es convertirse en un sujeto más de la investigación dando lugar a la presencia de sesgos en la indagación $n^{4}$.

Los sesgos son una constante amenaza a la validez y confiabilidad de los estudios, por lo que se recomienda estar alerta a ellos. Para evitar los sesgos en los estudios cualitativos se sugiere describir con el máximo de detalle los pasos que se siguieron en la investigación, esto hace que su aparición sea controlada, existiendo la triangulación (de tiempo, de espacio, de métodos, de datos, de teorías y observadores) como la estrategia más poderosa para eliminar las fuentes de error ${ }^{5}$.

En nuestro medio la presencia de publicaciones de artículos originales científicos en el campo de la salud pediátrica, cuya metodología haya sido cualitativa, es aún baja. En la Revista Chilena de Pediatría entre los años 2002 y 2016 se publicaron 8 estudios con metodología cualitativa, y en el 2017-2018 se publicaron 2 estudios con metodología cualitativa. Esto da la impresión que se está ampliando la riqueza metodológica e integración de equipos interdisciplinarios de investigadores cualitativos en las publicaciones (Tabla 1).

A modo de ejemplo de lo señalado en el párrafo anterior, destacan dos estudios cualitativos sobre el tema de la Lactancia Materna, recibidos este año. Uno de ellos es el estudio publicado en este número $\left(\mathrm{N}^{\circ} 5\right)$ de la revista, sobre las experiencias, creencias y actitudes de la donación de leche humana en mujeres de la provincia de Arauco, Chile, estudio que contribuye a la comprensión y conocimiento pediátrico de una práctica que es aceptada y considerada un acto altruista por las mujeres entrevistadas. Práctica que puede ser utilizada por las mujeres que amamantan en nuestro país y cuyo abordaje se logró través de las entrevistas en profundidad realizadas por un equipo interdisciplinario de investigadoras ${ }^{6}$.

El otro estudio, realizado en Bogotá, Colombia -por publicar- está fundamentado en la experiencia vivida por mujeres gestantes y en periodo de lactancia que permitió al equipo interdisciplinario de investigadores, a través de entrevistas en profundidad y grupos focales, un acercamiento a sus percepciones acerca de la Alimentación Complementaria, con el objetivo de 
identificar barreras y facilidades para el seguimiento de las recomendaciones nutricionales en relación al inicio temprano en niños y niñas entre 0 y 24 meses de edad, de un programa de atención integral a la primera infancia. El propósito del estudio fue contribuir a que este conocimiento permitiese una reorientación de las estrategias de intervención alimentaria y nutricional teniendo en cuenta la realidad sociocultural que rodea a las madres y o responsables del cuidado de los y las niñas.

Otro aspecto a destacar en el comité editorial de la Revista de Pediatría, es la incorporación de una profesional con experiencia en estudios con metodología cualitativa, lo que conlleva a ampliar las posibilidades de revisar y aprobar investigaciones en el marco del paradigma cualitativo.

Finalmente, la invitación es para los investigadores a formar equipos interprofesionales y cambiar el lente con el cual se observa la realidad y aproximarse con una mirada holística, flexible, contextualizada, comprensiva, que caracteriza el paradigma cualitativo, para entender las conductas que motivan y guían el actuar de las personas.

\section{Conflicto de intereses}

Los autores declaran no tener conflicto de intereses.

\section{Referencias}

1. Denzin NK, Lincoln YS. Handbook of qualitative research.Thousands Oaks, 1994.CA: Sage Publications.

2. Bartolomé M. Investigación cualitativa en educación: ¿comprender o transformar? RIE 1992; 20 (10):7-36.

3. Cook T, Reichardt CH. Métodos cualitativos y cuantitativos en investigación evaluativa. Ediciones Morata, S,L, $1^{\text {a }}$ ed., Madrid, 1986 Colección Pedagogía.

4. Martínez M. Criterios para la superación del debate metodológico "Cuantitativo/ Cualitativo” Rev Interamericana de Psicología 1999;33(1):79-107.

5. Straus A, Corbin J. Bases de la Investigación Cualitativa. Técnicas y procedimientos para desarrollar la teoría fundamentada. Primera edición (en español): Editorial Universidad de Antioquía, 2002 Sage Publications, Inc.

6. Ibarra J, Meza S, Aguayo K. Experiencias, creencias y actitudes sobre donación de leche humana en mujeres de la provincia de Arauco. Rev Chil Pediatr. 2018; Vol 89, No 5 Versión in press ID 602. http:// revistachilenadepediatria.cl/index.php/ rchped/article/view/602/764. 